\title{
Analysing the Symbology of Soviet Military City Plans
}

\author{
Martin Davis ${ }^{\mathrm{a}}$ *, Alexander J. Kent ${ }^{\mathrm{b}}$ \\ ${ }^{a}$ Royal Geographical Society (with IBG),UK, m.davis@rgs.org \\ ${ }^{b}$ Canterbury Christ Church University,UK, alexander.kent@canterbury.ac.uk \\ * Corresponding author
}

Keywords: Topographic maps, cold war, USSR

\begin{abstract}
:
The collapse of the Soviet Union has seen the emergence of its unprecedentedly comprehensive global military mapping programme and the commercial availability of a vast number of detailed topographic maps and city plans at several scales. This paper presents an analysis of the symbology devised by the Soviet Union for its series of secret military plans, which covered over 2,000 towns and cities outside the USSR. Analyses of symbol specification documents and the implementation of their symbology in a 1\% sample (19) of these plans allow its relationship with the urban characteristics of the towns and cities they symbolise to be explored.
\end{abstract}

In particular, this investigation assesses the extent to which the Soviet symbology is adopted across a variety of sociocultural and physical environments at 1:10,000 and 1:25,000 scales. This reveals new details of the most comprehensive, globally-standardised topographic symbology ever produced, incorporating 630 graphical symbols in total, with $47.0 \%$ and $52.1 \%$ of these used in the sample of maps at both scales respectively. Elements of the physical environment account for the largest components of the symbology, with 'Hydrography and Coasts' the largest feature class at 1:10,000 (84 symbols) and 'Vegetation and Soils' at 1:25,000 (66 symbols). A comparative analysis with the OpenStreetMap symbology indicates scope for Soviet mapping to be used as a valuable supplementary topographic resource in a variety of existing and future global mapping initiatives, including humanitarian crisis mapping. This leads to a conclusion that the relevance and value of Soviet military maps endures in modern applications, both as a source of data and as a means of overcoming contemporary cartographic challenges relating to symbology, design and the handling of large datasets.

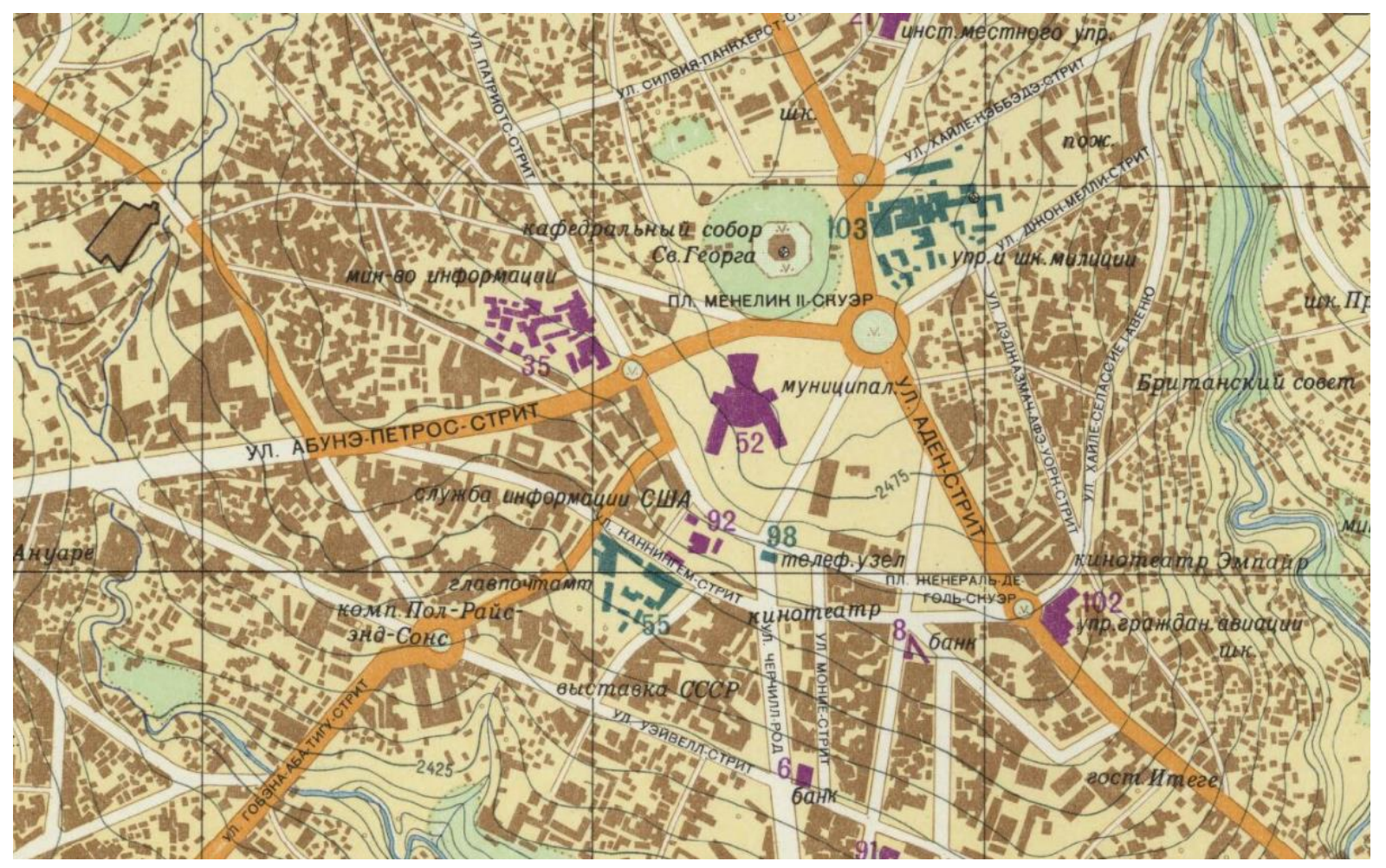

Figure 1. Extract from the 1:10,000 Soviet plan of Addis Ababa, Ethiopia (1978) 